Revistade
Economild
Contemporâned

\title{
DETERMINANTES DO REPASSE CAMBIAL: UMA RESENHA COM FOCO NO CASO BRASILEIRO
}

\author{
Thallis Macedo de Assis ${ }^{a}$ \\ Luiz Fernando Cerqueira Fonseca ${ }^{b}$ \\ Carmem Aparecida do Valle Costa Feijóc

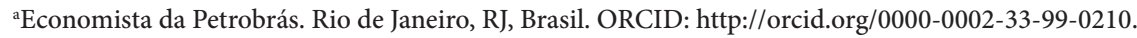

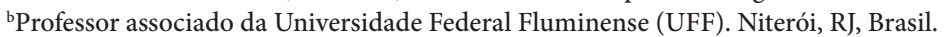 \\ ORCID: http://orcid.org/0000-0001-6781-2247. \\ 'Professora titular do Departamento de Economia da Universidade Federal Fluminense (UFF) e \\ pesquisadora do CNPq. Niteroi, RJ, Brasil. ORCID: http://orcid.org/0000-0002-6376-4599.
}

Artigo recebido em 21/12/2017 e aceito para publicação em 18/01/2019.

RESUMO: A taxa de câmbio constitui um dos principais preços da economia. Suas flutuações têm importantes impactos sobre os preços domésticos, portanto, sobre a condução e credibilidade da política monetária. Este artigo apresenta uma ampla resenha da literatura sobre o repasse cambial, e nesse sentido contribui para organizar o debate sobre o tema, que é de especial interesse para se entender o processo inflacionário brasileiro. Um aspecto a ser destacado é que identificamos que o repasse cambial pode variar entre grupos de países devido à existência de uma hierarquia do sistema monetário internacional, fato que não é tratado explicitamente na literatura sobre repasse cambial. $\mathrm{O}$ artigo inclui também trabalhos empíricos sobre repasse cambial no Brasil. Conclui que os determinantes macro e microeconômicos do repasse cambial fazem parte de um todo que precisa ser entendido no nível das firmas para melhor explicar o comportamento agregado dos preços.

PALAVRAS-CHAVE: repasse cambial; ambiente inflacionário; heterogeneidade setorial no repasse cambial; assimetria no repasse cambial; hierarquia de moedas.

CLASSIFICAÇÃO JEL: E31; F31.

Correspondência para: Carmem Aparecida do Valle Costa Feijó

Contato: cbfeijo@gmail.com 


\section{DETERMINANTS OF THE EXCHANGE RATE PASS- THROUGH: A SURVEY OF THE BRAZILIAN CASE}

ABSTRACT: The exchange rate is one of the main prices of the economy. Its fluctuations have important impacts on domestic prices and therefore on the conduct and credibility of monetary policy. This paper presents a broad review of the literature on the exchange rate pass-through and it gives a contribution in the sense to organize the debate on the subject, which is of special interest to the understanding of Brazil's inflationary process. It has been identified that the phenomenon of exchange rate pass-through may vary among groups of countries as a result of a hierarchy within the international monetary system, a fact that is not explicitly addressed in the specialized literature. The paper also includes empirical studies on exchange rate pass-through in Brazil. It concludes that the macro and microeconomic determinants of exchange rate transfers are part of a whole that needs to be understood at the level of firms to better explain the aggregate behavior of prices.

KEYWORDS: pass-through; inflationary environment; sectorial heterogeneity in the pass-through; pass-through asymmetry; money hierarchy. 


\section{INTRODUÇÃO}

A taxa de câmbio constitui um dos principais preços da economia. Para economias emergentes que adotam regime de metas para a inflação, como a brasileira, a influência da taxa de câmbio sobre os preços é crucial para a estabilidade desse regime. ${ }^{1} \mathrm{O}$ objetivo deste trabalho é, além de revisar a literatura sobre repasse cambial, apontar as principais linhas de discussão na literatura internacional sobre as evidências encontradas a favor de assimetria no repasse cambial, com destaque para trabalhos empíricos para o caso brasileiro. Desse modo, este artigo traz como contribuição fornecer uma base para o debate sobre repasse cambial no Brasil. Nesta resenha destacamos, em especial, o papel que tem a desempenhar sobre o repasse cambial o fato de sistemas monetários serem hierárquicos, ${ }^{2}$ ou seja, um dado da realidade econômica global, ${ }^{3}$ tratado por diversos autores, mas com sua relação direta com o repasse cambial não explicitada.

Dados os níveis de preços interno e externo, é a taxa de câmbio que regula o poder de compra internacional da moeda doméstica, e, em um mundo de repasses cambiais incompletos, ao menos no curto prazo, e com um "curto prazo" na prática longo o suficiente para produzir consideráveis flutuações em preços relativos, os movimentos da taxa de câmbio nominal são de crucial importância (BURNSTEIN et al., 2005; BURNSTEIN e GOPINATH, 2014), de modo que a competitividade da indústria nacional, o custo de insumos importados e a capacidade de absorção de bens de consumo globais são determinados pela taxa de câmbio, ao menos no curto prazo. Assim, a taxa de câmbio é um preço com importância distinta na macroeconomia, tendo sua volatilidade importantes implicações sobre a estabilidade econômica, sobretudo sobre a estabilidade dos preços. Minella et al. (2003), inclusive, destacam as dificuldades de se construir credibilidade para a autoridade monetária em um ambiente de elevada volatilidade cambial. Assim, torna-se fundamental o entendimento do repasse cambial aos preços em uma economia.

$\mathrm{Na}$ literatura, em geral, define-se o repasse da taxa de câmbio (moeda doméstica/ moeda estrangeira) para os preços domésticos (pass-through) como o crescimento percentual nos preços domésticos dada, ceteris paribus, uma depreciação de $1 \%$ na moeda doméstica diante da moeda estrangeira de referência - em geral o dólar americano (USD), por ser a principal moeda em transações internacionais (CALVO e MISHKIN, 2003; GOLDBERG e TILLE, 2016). Isto é, a elasticidade do nível geral de

\footnotetext{
1 Ver Minella et al. (2003), Mishkin (2004), Nordstrom et al. (2009), Ghosh et al. (2016).

2 Wray (1998).

3 Prates (2005), Rossi (2010), Kaltenbrunner (2015), Paula et al. (2017), Fritz et al. (2018).
} 
preços à taxa nominal de câmbio. O repasse cambial aos preços de importação muda quando os preços são fixados (ou estabilizados - ver literatura de pricing to market) ${ }^{4}$ na moeda do produtor, producer currency pricing (PCP), na moeda do mercado de destino, local currency pricing (LCP), ou ainda em uma moeda que não circula nas transações cotidianas em nenhuma das economias envolvidas na transação, nesse caso sendo chamada de uma moeda veículo, vehicle currency pricing (VCP). Teoricamente PCP implica repasse cambial aos preços de importação na economia de destino, completo; LCP implica repasse zero na economia de destino; em caso de VCP, o repasse vai depender das taxas de câmbio bilaterais do produtor e do importador em relação à moeda veículo.

Há estudos que apontam a relevância distinta para a taxa de câmbio nas discussões macroeconômicas nos países emergentes, sobretudo para os que adotam o regime de metas para a inflação (CALVO e REINHART, 2002; CALVO e MISHKIN, 2003; MISHKIN, 2004, NORDSTROM et al., 2009; GHOSH et al., 2016). No caso de autores como Calvo e Mishkin (2003), o foco da distinção dos países emergentes está em suas instituições de política econômica, consideradas menos maduras e não tão bem estabelecidas perante o público em comparação com as economias desenvolvidas, o que resulta, em última análise, em problemas de credibilidade dos policymakers nessas economias, mas também reconhecem problemas relacionados ao subdesenvolvimento de mercados financeiros locais e maior vulnerabilidade a sudden stops nos fluxos de capitais. Os autores também destacam a maior propensão nessas economias, em caso de instabilidades macroeconômicas severas, de haver substituição monetária, dado que já existem moedas bem estabelecidas e com poder de compra internacional, isto é, moedas em que os preços de bem comercializáveis são fixados, como o dólar americano. Essa percepção indica que os autores admitem a existência de uma hierarquia no sistema monetário internacional. Em outra linha de argumentação quanto à existência de uma hierarquia de moedas, Wray (1998) enfatiza as diferenças no grau de liquidez internacional das moedas, distinguindo aquelas que emitem passivos na própria moeda e aquelas que têm mais limitações em fazê-lo. Dessa forma, o grau de liquidez internacional das moedas de países emergentes é menor em relação às economias desenvolvidas, o que coloca as moedas dos países emergentes em posição inferior na escala de liquidez internacional, e torna essas economias mais vulneráveis a choques

4 Knetter (1993) estuda o caso de pricing to market, em que há o que ele chama de local currency pricing stabilization, que se constitui quando uma firma exportadora diante de um choque cambial ajusta suas taxas de markup de maneira destino-específica, de modo a estabilizar os preços na moeda do país importador. 
externos. ${ }^{5}$ Portanto, quer seja como Calvo e Mishkin (2003) ou como Wray (1998), ao reconhecermos a existência de uma hierarquia de moedas e adicionarmos essa dimensão como um problema a ser considerado na escolha da moeda de fixação de preços no comércio internacional, ${ }^{6}$ temos motivos teóricos para esperar maior instabilidade monetária em países em desenvolvimento associada, inclusive, a maiores repasses cambiais, pois haveria nesses países menor participação de bens nas pautas de importação cujos preços são fixados em moeda local (BURNSTEIN e GOPINATH, 2014).

A literatura acerca do repasse cambial pode ser dividida em dois grandes grupos de acordo com o foco de análise. O primeiro se volta às inter-relações macroeconômicas da taxa de câmbio e o ambiente macroeconômico em que se dão reajustes de preços para explicar as flutuações no repasse cambial ao longo do tempo. O segundo preocupa-se com as estruturas de mercado em que as firmas operam para determinar as estratégias de precificação no mercado internacional, portanto, o repasse cambial.

$\mathrm{O}$ artigo representativo da primeira linha de análise e referência para explicar o declínio no repasse cambial que parece ter ocorrido nas décadas 1980 e de 1990 é Taylor (2000). O autor revisa trabalhos que encontram evidências de redução do repasse cambial nas duas décadas que antecederam seu trabalho em relação as décadas anteriores, com foco no comportamento do dólar americano. Ele acredita que o ponto fundamental dessa mudança está na mudança do ambiente inflacionário (e seu argumento pode ser entendido para os 17 anos que seguiram ao seu trabalho, dado que confirmou a tendência de maior estabilidade inflacionária, sobretudo para a América Latina, que, mesmo diante de diversos episódios de instabilidade em diferentes momentos para diferentes países, não viu o ressurgimento de seus persistentes processos inflacionários vigentes na segunda metade do século XX). ${ }^{7}$ Taylor (2000) argumenta que a redução global da inflação entre os anos 1980 e 1990 se deve em grande medida à mudança na condução da política monetária. Para esse autor, a adoção de modelos, pelos principais bancos centrais, que baseiam a política monetária em regras reduzindo a discrição, contribuiu para a redução das taxas de inflação no mundo, com os preços em geral mais estáveis em um ambiente inflacionário menos volátil.

5 Wray (1998) oferece uma clara explicação da existência de hierarquia dos passivos monetários em uma economia que pode ser aplicada às moedas no sistema monetário global, dado que não há dúvida de que o dólar tem liquidez internacional muito superior à do real. Ver também Paula et al. (2017) e Fritz et al. (2018).

$6 \mathrm{Na}$ literatura internacional aparece nos papers relacionados a international trade invoicing, na qual uma revisão e novas evidência empíricas podem ser vistas em Golberg e Tille (2016).

7 Campa e Goldberg (2005) chegam a citar o caso brasileiro como exemplo de elevado choque cambial (transição do câmbio fixo (crawling peg) para o flutuante em janeiro de 1999) que não levou a uma elevação proporcional nos preços ao consumidor, o que denotaria a queda do repasse cambial nas últimas décadas. 
A segunda linha tem antecedentes teóricos em Dornbusch (1987), que busca explicações para o comportamento de ajustamento de preços após choques cambiais, essencialmente em aspectos dos mercados em que as firmas que transacionam internacionalmente operam, e em Krugman (1986), que é uma das principais referências na literatura de pricing to market, que, de maneira bem geral, admite a possibilidade de markups distintos para mercados de destinos distintos por parte de uma firma exportadora (o que necessita de algum grau de segmentação de mercado, que, por sua vez, depende de características institucionais e, também, fundamentalmente das características do bem transacionado). Todavia, o artigo representativo dos trabalhos voltados a essa discussão nas duas últimas décadas, sobretudo do ponto de vista empírico, é o de Campa e Goldberg (2005), que defende explicitamente que a flutuação do repasse ao longo do tempo e sua variação entre países depende muito mais das diferenças na composição de pautas de importação do que das característica macroeconômicas, e isso porque o comportamento do repasse cambial varia mais entre setores do que entre países (KNETTER, 1993; CAMPA et al., 2008).

Há ainda um tópico que perpassa ambas as linhas de estudo, de cunho fundamentalmente empírico, que é constituído pela assimetria no repasse cambial. Isto é, existem diversos estudos que, com distintas metodologias e distintos focos empíricos, têm encontrado evidência favorável a repasses distintos em caso de apreciação ou depreciação da moeda doméstica (POLLARD e COUGHLIN, 2004; CAMPA et al., 2008; DELATTE e LOPEZ-VILLAVICENCIO, 2012; BUSSIÈRE, 2013; PIMENTEL et al., 2016; PIMENTEL, 2017; ASSIS, 2017; BRUN-AGUERRE et al., 2017).

A próxima seção discute os artigos de cunho mais macroeconômico, especificidades de economias em desenvolvimento em relação às desenvolvidas e foca-se na literatura aplicada para o caso brasileiro. Na terceira seção nos voltamos à microeconomia do repasse cambial. Na quarta discutimos, teoricamente, porque pode-se esperar assimetria no repasse cambial em uma economia e apresentamos evidências empíricas desse fenômeno. A última resume o que concluímos ser de essencial importância na literatura neste trabalho revisada, sobretudo para o debate em torno da taxa de câmbio no Brasil.

\section{A MACROECONOMIA DO REPASSE CAMBIAL}

Há razões para que o repasse cambial seja dependente de regime, isto é, difira em intensidade em caso de câmbio fixo, flutuante ou flutuação suja. Barbosa-Filho (2008) aponta para o caso brasileiro uma flutuação suja assimétrica, que ocorre quando a autoridade monetária parece intervir mais em momentos de desvalorização cambial do que em momentos de valorização. Em caso de câmbio fixo, uma mudança na taxa 
de câmbio que possa ser entendida como permanente estimula os formadores de preços a repassarem o impacto da variação cambial sobre os custos integralmente. De maneira contrária, quando o câmbio é flutuante, a não ser que o formador de preço perceba uma mudança no nível médio da taxa de câmbio, uma mudança brusca tende a ser vista como temporária. Quando há interferência do banco central restringindo a flutuação, se esta é corretamente percebida pelos agentes, estes podem aprender o comportamento da autoridade monetária e agir de acordo, especulando no mercado de câmbio quando acreditam que a taxa se afastou de um intervalo perseguido pela autoridade monetária. Caso a autoridade monetária tenha credibilidade em sua intervenção cambial, a especulação tende a ser estabilizadora, ${ }^{8}$ caso contrário, a especulação tende a produzir movimentos cambiais muito intensos, que aumentam a incerteza na economia e podem ter impactos sobre a intensidade do repasse cambial. Claro que mudanças de preços dependem do poder de mercado do formador de preço, de forma que é fundamental para determinação da intensidade do repasse cambial as estruturas de mercado presentes nos diferentes setores da economia (CAMPA et al., 2008).

Com foco em características macroeconômicas, Goldfajn e Werlang (2000), realizando um estudo em painel com 71 países entre 1980 e 1998 (com dados mensais), encontram que o nível de sobrevalorização da taxa real de câmbio (desvio de sua tendência de longo prazo gerada por meio do filtro HP), o grau de abertura da economia (medido pela soma das exportações mais importações como porcentagem do PIB), o hiato do produto (desvio do PIB em relação à sua tendência de longo prazo medida pelo filtro HP) e o nível de inflação de uma economia afetam o pass-through.

Os autores encontram que a sobrevalorização da taxa real de câmbio, medida a partir do desvio da taxa real de câmbio de sua tendência de longo prazo estimada pelo filtro HP, ${ }^{9}$ está negativamente correlacionada com o nível de repasse cambial, o que pode ser entendido da seguinte forma: se anteriormente a uma significativa desvalorização cambial a moeda doméstica estava sobreapreciada em termos reais, então o ajuste virá principalmente pelo realinhamento dos preços relativos entre comercializáveis e não comercializáveis na economia doméstica, tendo menores consequências sobre o aumento generalizado dos preços.

Donayre e Panovska (2016), estudando Canadá e México de 2001 a 2013 por meio do uso de Vetor Autorregressivo Bayesiano com limiar (Bayesian Threshold Vector Autoregression),

8 Especuladores apostam a favor do retorno da taxa de câmbio para os planos da autoridade monetária. Ocorre que esse cenário é menos provável quando não há planos anunciados de maneira transparente, levando a maior incerteza no mercado cambial.

9 Algo como um desvio em relação a um nível (ou trajetória) de câmbio considerado normal pelo mercado. 
encontram que, quanto maior o hiato do produto (medido como desvio percentual do produto potencial estimado pelo filtro HP), mais a demanda está aquecida e, portanto, maior é a propensão das firmas a repassar à demanda final os impactos de uma desvalorização cambial. Os autores encontram regimes distintos de repasse cambial, dependendo da fase do ciclo econômico, sendo maior o repasse em regime de demanda aquecida (taxa de crescimento acima do limiar estimado).

A abertura comercial tem impactos distintos sobre o repasse cambial dependendo da região, sendo pouco significativa para Europa e Ásia, positivamente correlacionada com o repasse cambial na África e na Oceania, e negativamente na América. O fato de maior abertura levar a aumento no repasse está ligado ao fato de maior abertura estar relacionada à maior dependência de importações. O maior coeficiente de importação na cadeia produtiva doméstica implica maior potencial para absorção direta de choques cambiais. $\mathrm{O}$ fato de a maior participação de importados na economia contribuir para um maior repasse cambial está em linha com alguns resultados teóricos apresentados em Dornbush (1987). Para esse autor, a maior participação de importados na cesta de consumo serve como proxy para a participação de firmas estrangeiras nos diversos mercados presentes na economia e, quanto maior for esta participação, menor deve ser a competição doméstica em um dado mercado. Esse fenômeno permite maior repasse de choques de custos por parte das firmas estrangeiras ${ }^{10}$ operando nesse mercado. $\mathrm{O}$ fato de na América Latina o repasse cambial estar negativamente correlacionado com a abertura indica que o efeito de acirramento competitivo promovido pela abertura domina, levando economias mais abertas no continente, tudo o mais constante, a terem menor repasse cambial.

Goldfajn e Werlang (2000) encontram que 12 meses após uma variação de 1\% na taxa nominal de câmbio, tudo o mais constante, há uma variação de $0,245 \%$ no nível de preços ao consumidor para economias desenvolvidas e $0,394 \%$ para economias emergentes. $\mathrm{O}$ maior repasse em economias emergentes pode ser explicado em boa medida pelo fato de em muitas dessas economias o processo inflacionário ser mais persistente e o período amostral dos autores incluir período de taxas muito mais elevadas em economias emergentes (como o Brasil) do que nos países desenvolvidos. $\mathrm{O}$ nível da taxa de inflação parece estar relacionado tanto com a persistência do processo inflacionário quanto com a incerteza, ${ }^{11}$ fatores que impelem os formadores de preços

${ }^{10}$ Uma desvalorização da moeda local representa queda de receita marginal por parte da firma estrangeira, na moeda da economia na qual é residente, dado o preço do produto em moeda local, e torna os eventuais insumos importados da economia baratos em sua moeda.

${ }^{11}$ Mankiw et al. (2003) encontram relação positiva entre o nível da taxa de inflação e a dispersão nas expectativas tanto dos consumidores quanto dos forecasters profissionais nos EUA. 
a repassarem choques de custos (TAYLOR, 2000). Abaixo discutimos com mais profundidade porque, teoricamente, pode-se esperar maior repasse em economias em desenvolvimento do que em economias desenvolvidas. Claras diferenças no repasse cambial também podem ser vistas para outras classificações dos países da amostra para o período de 12 meses: coeficiente de 0,188 para países da OECD contra 0,754 para economias não participantes do grupo. ${ }^{12} \mathrm{E}$ ainda a influência dos processos inflacionários sobre o repasse cambial é destacada pelos autores que atribuem maior repasse cambial na América Latina que nos demais continentes, exceto pela Ásia ${ }^{13}$ (para o período de 12 meses a Ásia apresenta o maior coeficiente de repasse cambial, mas para um horizonte de 24 meses a América Latina apresenta o maior repasse), à espiral inflação-depreciação vivida por diversos países latino-americanos no período amostral (anteriormente às respectivas estabilizações monetárias. No Brasil esta foi alcançada com o Plano Real em 1994). ${ }^{14}$

Taylor (2000) defende teoricamente que, sob inflação baixa e estável, a persistência de choques sobre os preços tende a ser reduzida. Assim, em um ambiente de baixa e menos volátil inflação proporcionado por uma política monetária calcada em regras, as expectativas de inflação estarão ancoradas, o que reduz a propensão das firmas a reagirem a choques de custos, entre eles a variação cambial, dado que estes não influenciam a dinâmica geral dos preços no longo prazo (visto que no longo prazo acredita-se que os preços seguirão na velocidade anunciada pela autoridade monetária).

De Mendonça e Tiberto (2017), em uma análise de painel de 114 países em desenvolvimento, ${ }^{15}$ de 1999 a 2013, investigam a capacidade de a credibilidade da autoridade monetária ${ }^{16}$ reduzir o impacto de choques cambiais sobre os preços. Desenvolvem um modelo empírico que tem a inflação dos preços ao consumidor como variável depen-

12 Um coeficiente de 0,188 significa que, para um choque de desvalorização cambial de $1 \%$, tudo mais constante, em 12 meses se observará uma variação adicional nos preços ao consumidor de $0,188 \%$, que não ocorreria no caso de não ter havido, na taxa de câmbio, choque.

${ }^{13}$ O período amostral inclui a crise cambial que se abateu sobre diversas economias asiáticas na década de 1999 (Tailândia, Malásia, Coreia do Sul e Filipinas). A esse respeito ver, por exemplo, Corden (2002).

${ }^{14}$ Os coeficientes de repasse cambial acumulado em 12 meses por continente estimados por Goldfajn e Werlang são: América: 0,692; Europa: 0,360; África: 0,643; Oceania: 0,158; Ásia: 0,712.

15 Os países na amostra representam $80 \%$ do total dos países em desenvolvimento, segundo a classificação do FMI (DE MENDONÇA e TIBERTO, 2017).

${ }^{16}$ O efeito perceptível de uma política monetária crível é a manutenção das expectativas dos agentes em torno da meta de inflação anunciada. Uma política monetária mais crível deve aumentar o peso da meta anunciada pela autoridade monetária na formação de expectativas de inflação, reduzindo a inércia inflacionária, portanto, o impacto de choques que fogem ao controle da autoridade monetária, pois acredita-se que, apesar do choque, o comprometimento da autoridade monetária fará convergir a inflação para a meta em um prazo razoável. 
dente e inclui um termo que mensura a soma da variação cambial nominal (na taxa de câmbio entre a moeda local e o dólar americano) à variação do índice geral de preços nos EUA, de forma a controlar os efeitos da variação cambial, líquidos de variações nos preços do produtor, sendo os preços americanos uma proxy destes (maior economia do mundo e emissora da principal moeda em transações internacionais), e inclui também um termo que interage uma medida de credibilidade da política monetária com o termo previamente descrito. Desse modo espera-se que o coeficiente associado ao termo sem interação seja positivo e o do termo com interação com a credibilidade seja negativo, o que indica que, quanto mais o público acredita no comprometimento e na capacidade da autoridade monetária em cumprir seus planos anunciados, menor o repasse cambial. Os autores, controlando para variáveis como renda per capita (como proxy de nível geral de desenvolvimento econômico), indicadores monetários, abertura comercial, abertura financeira, existência de controle cambial, aversão ao risco nos mercados financeiros internacionais e indicador fiscal, encontram que a credibilidade da autoridade monetária é capaz de reduzir significativamente o efeito de choques cambiais sobre os preços internos. Para autoridades monetárias com alta credibilidade (indicador de credibilidade próximo de 1) é possível até anular os efeitos do repasse cambial sobre os preços ao consumidor. Os efeitos benéficos da credibilidade no controle do nível inflação também são observados no controle da volatilidade da inflação. Encontram também evidência favorável à abertura financeira, ao desenvolvimento econômico (aproximado pela renda per capita), à estabilidade fiscal e a algum controle sobre a taxa de câmbio como redutores tanto do nível de inflação dos preços ao consumidor como da volatilidade dessa variável. Para o caso brasileiro, de Mendonça e Tostes (2014) encontram evidência que a credibilidade da política monetária ${ }^{17}$ é capaz de reduzir o repasse cambial aos preços livres. Mas os autores encontram efeito ainda mais significativo para a credibilidade fiscal, ${ }^{18}$ esta reduzindo o repasse cambial para os preços em geral e também para as expectativas de inflação.

Choudhri e Hakura (2006) suportam empiricamente as ideias desenvolvidas em Taylor (2000). Em uma análise de 71 países entre 1970 e 2000, encontram que a inflação domina outros fatores macroeconômicos na explicação das variações entre países do repasse cambial aos preços de importação. Juntilla e Kohonen (2012), analisando dados trimestrais de 1975 ao terceiro trimestre de 2009 para EUA, Itália, Alemanha,

${ }^{17}$ Quanto mais distante do centro da meta de inflação, mas ainda dentro de bandas de tolerância anunciadas, menor a credibilidade. Expectativas de inflação fora do intervalo de meta anunciado denota ausência de credibilidade.

18 Se a dívida pública como proporção do PIB for inferior a 40\%, cai linearmente a partir desse patamar e é zero a partir de $60 \%$. Os resultados dos autores são robustos à ampliação desse intervalo de $40 \%-60 \%$. 
Canadá, Reino Unido, Suécia, Dinamarca, Espanha e Austrália, encontram também evidência de dependência do repasse cambial com o nível da inflação. Estudam a presença de regimes de repasse cambial distintos, a depender do nível da inflação. O repasse é significativamente maior em ambiente de alta inflação (o threshold ou os parâmetros de transição que descrevem a transição de regime são estimados endogenamente). Lin e Wu (2012), em um estudo de Taiwan com dados mensais de 1981 a 2008, encontram uma novidade empírica, que é uma significativa elevação do repasse cambial em ambiente de deflação.

Burnstein e Gopinath (2014) oferecem uma boa resenha dos achados empíricos mais recorrentes na literatura de repasse cambial. De modo geral os autores observam que a taxa de câmbio real baseada em índices de preços ao consumidor segue de perto as flutuações da taxa de câmbio nominal, sendo bastante persistente (que é verdade para o Brasil, o que pode ser visto plotando-se a taxa nominal de câmbio R\$/US\$ e taxa real referente a essa mesma taxa de câmbio calculada com base no IPCA brasileiro e no CPI estadunidense); o repasse cambial para os preços de importação ("at the dock" ou border prices) é maior que o repasse cambial para os preços ao consumidor (BURNSTEIN et al., 2005; CAPÍSTRAN et al., 2012); o repasse cambial para preços de importação varia consideravelmente entre países, é menor nos EUA tanto no curto como no longo prazo e incompleto em um prazo de dois anos após o choque; há consideráveis desvios da PPP relativa para um bem produzido em uma mesma economia e vendido em diferentes economias de destino (ATKENSON e BURNSTEIN, 2008), fornecendo um modelo teórico capaz de reproduzir esse tipo de achado empírico, com base na literatura de pricing to market.

Olhando mais de perto o caso brasileiro, Albuquerque e Portugal (2005), usando uma amostra de frequência trimestral de 1980 a 2002, encontram evidência de que há um significativo decrescimento do repasse cambial pós-estabilização inflacionária com o Plano Real, o que está em linha com o encontrado por Goldfajn e Werlang (2000). Períodos de alta inflação (como a década de 1980) estão correlacionados com alta persistência inflacionária, o que leva os agentes a perceberem possíveis choques cambiais sobre a inflação como permanentes e também uma nova redução, esta mais abrupta, após a adoção do câmbio flutuante, sendo o repasse cambial pós-1999 mais estável, o que constitui evidência favorável à dependência do repasse cambial em relação ao regime cambial. Antes de 1999, Albuquerque e Portugal (2005) estimam que um choque na taxa de câmbio em $t$ é integralmente repassado aos preços, medidos pelo IGP-DI (1\% de variação no câmbio levando a mais 1p.p. de taxa de inflação) em $t+4$, na ausência de outros choques sobre os preços. Após 1999, apenas 32\% da variação cambial é repassada ao IGP-DI no mesmo período e nas mesmas condições. Para o IPCA o repasse é completo, ceteris paribus, dois trimestres após o choque, antes de 
1999, após o mesmo período apenas 7\% da variação cambial é repassada. Para o IPA-DI encontra-se um repasse quase completo até o terceiro trimestre após o choque cambial em todo o período amostral. Aplicando a mesma metodologia desses autores para o período de 1994 a 2014, Almendra et al. (2015) também encontram evidência de redução do repasse cambial com a adoção do câmbio flutuante e mais rápido e intenso repasse para o IPA do que para o IPCA, e, ainda, incluindo a possibilidade de repasse assimétrico, encontram maior coeficiente de repasse em caso de desvalorizações cambiais do que em caso de apreciações. Esses resultados apontam para outra característica do repasse cambial; ele tende a reduzir ao longo da cadeia produtiva, isto é, maior para preços de produtos importados, depois um pouco menor para preços no atacado e ainda menor para preços ao consumidor final, o que pode sugerir impactos da taxa de câmbio sobre taxas de markup ao longo da cadeia produtiva de uma economia, tudo o mais constante. Contudo, tal afirmação necessita que os custos de distribuição dos bens ao longo da cadeia produtiva estejam bem representados entre os controles aplicados na investigação empírica. Todavia, esse resultado de decaimento do repasse cambial ao longo da cadeia produtiva aparece em diversos trabalhos, como o de McCarthy (2000), em uma aplicação para economias industrializadas desenvolvidas; o de Choudhri et al. (2005), em uma aplicação para os países do G7, excluindo os EUA; o de Capístran et al. (2012), para a economia mexicana; e o de Belaisch (2003), para o Brasil (todos os destacados aqui são baseados em análises de funções impulso-resposta de modelos VAR).

Uma série de estudos na literatura econômica nacional se devotou à mensuração do repasse cambial por meio do uso de modelos VAR. Os autores em geral consideram proxies para o nível de atividade (como o índice de produção industrial do IBGE), o preço do petróleo como forma de controlar choques de preços externos e, claro, o índice de preços de interesse e a taxa nominal de câmbio.

Belaisch (2003) estima um VAR(2) para o período de julho de 1999 a dezembro de 2002, a partir dos resíduos ortogonalizados pela Decomposição de Cholesky. O coeficiente de repasse cambial para o período $t+j$, dado um choque unitário na taxa de nominal de câmbio no período $t+1$, é igual à razão entre variação no logaritmo natural do índice de preço doméstico e à variação do logaritmo natural da taxa de câmbio nominal, ambas acumuladas do período do choque até $j$. A autora encontra que o repasse cambial sobre o IPA ${ }^{19}$ é muito mais persistente e veloz do que sobre o IPCA (o impacto sobre o IPA tem pico no primeiro mês após o choque cambial e permanece significativo por oito meses, enquanto o impacto sobre o IPCA atinge o pico ao final

19 Índices de preços ao produtor amplo calculado pelo IBRE/FGV. 
do primeiro trimestre após o choque e perde significância estatística em seguida). $\mathrm{O}$ IGP-DI responde rapidamente também, mas o impacto tem menor intensidade e duração que sobre o IPA. Os comercializáveis são, dentre os preços ao consumidor, os mais sensíveis a choques cambiais, e os livres têm um comportamento similar, porém com menor intensidade. O impacto sobre os não comercializáveis é pequeno, porém persiste por 12 meses o que é consistente com a noção de que os não comercializáveis sofrem impactos de segunda ordem após choques cambiais (o impacto inflacionário direto sobre os comercializáveis é com alguma defasagem repassado aos não comercializáveis). ${ }^{20}$ Os preços administrados reagem mais rapidamente que os livres, mas o impacto sobre esses é menos persistente, perdendo significância estatística após um trimestre. A autora, então, conclui que o impacto sobre os preços, "excluindo os comercializáveis, após um choque na taxa de câmbio, é modesto. Após dois trimestres o crescimento na inflação é próximo de zero" (tradução livre da afirmação de BELAISCH, 2003, p. 11). Quanto ao repasse cambial, a autora identifica um repasse em 12 meses, esperado, de 53\% para o IGP, 120\% para o IPA, 17\% para o IPCA cheio, $15 \%$ para os livres, assim como para os comercializáveis, $5 \%$ para os administrados e $12 \%$ para os não comercializáveis.

Minella et al. (2003) incluem, em sua estimação para o período de setembro de 1994 a dezembro de 2002, o spread de taxas de juros entre títulos do tesouro medido pelo EMBI $+{ }^{21}$ como forma de controlar as crises financeiras ocorridas no período (mexicana, do Sudeste Asiático, russa, argentina e brasileira), e também a média mensal da taxa Selic/over efetiva para controlar decisões de política monetária. Diferentemente de Belaisch (2003), Minella et al. (2003) estimam um repasse cambial mais elevado para os preços administrados do que para os livres. Os autores estimam o repasse cambial como a razão entre a variação no nível de preços acumulada em 12 meses e o valor do choque cambial no primeiro desses 12 meses (note que difere do procedimento adotado por BELAISCH, 2003). Assim, estimam um repasse cambial de 32,7\% para preços administrados e $17 \%$ para preços livres. Retirando o último semestre de 2002 da amostra, o repasse cambial para os preços administrados é 19,7\% e 7,8\% para preços livres (é considerável a queda nos valores esperados; mas, considerando um nível de confiança de 95\%, os valores de repasse para cada uma das categorias de preços não são estatisticamente diferentes entre as duas estimações). Para o IPCA cheio o

\footnotetext{
${ }^{20}$ Alguns comercializáveis podem ter comercializáveis como insumo e/ou pode haver um movimento de reequiparação de preços relativos.

${ }^{21}$ Emerging Market Bonds Index Plus. De fato os autores usam o EMBI para o período de setembro de 1994 a dezembro de 1998 e o EMBI+ para o restante da amostra.
} 
repasse foi de $17,9 \%$ na amostra cheia e de $14,1 \%$ na amostra reduzida. Considerando apenas o período de metas de inflação, julho de 1999 e dezembro de 2002, o repasse cambial é menor, $20 \%$ para os administrados, $11,3 \%$ para os livres e $13,1 \%$ para o IPCA cheio. Contudo, os valores para os preços administrados e livres não são estaticamente significativos no período do regime de metas, provavelmente pela escassez de observações.

Nogueira Júnior (2007) analisa o repasse cambial e o fear of floating em um conjunto de países desenvolvidos (Canadá, Reino Unido e Suécia) e emergentes (Brasil, República Tcheca, México, África do Sul e Coreia do Sul) que adotaram o regime de metas de inflação. O autor identifica, por meio das metodologias utilizadas por Calvo e Reinhart (2002) e Ball e Reyes (2004), uma queda na intervenção da taxa de câmbio em todos os países após a adoção do regime de metas de inflação. A questão é se a intervenção na taxa de câmbio advém de um fear of inflation ou de um medo de flutuar mais generalizado. Uma autoridade monetária em um país que adote o regime de metas de inflação, ao identificar um elevado repasse cambial aos preços em sua economia, teria incentivo para buscar intervir na taxa de câmbio, de modo que o fear of inflation pode levar a um comportamento típico de fear of floating, mas o segundo seria caracterizado por uma atenção a movimentos na taxa de câmbio que não condiz com o regime de metas de inflação. Isto é, a observação de intervenções cambiais que não têm relação clara com o cumprimento das metas estabelecidas publicamente para o policymaker. Com essa perspectiva, Nogueira Júnior (2007) analisa dados macroeconômicos (reservas internacionais, taxas de juros, taxas de câmbio das moedas domésticas por unidade de dólar americano, taxa de inflação, taxa de crescimento do produto) entre janeiro de 1985 a dezembro de 2004 para os países desenvolvidos e de janeiro de 1995 a dezembro de 2004 para os países emergentes. O autor conclui que o repasse cambial é menor para economias desenvolvidas do que para economias emergentes, e que cai significativamente, em ambos os casos, após a adoção do regime de metas de inflação (sua metodologia de mensuração do repasse é a mesma de MINELLA et al., 2003). Contudo, afirma que a taxa de câmbio permanece como um importante determinante da taxa de inflação, mesmo após a adoção do regime de metas, o que justificaria as reações da maioria dos bancos centrais nas economias analisadas a movimentos na taxa de câmbio, ou seja, tais reações buscam evitar a difusão do repasse cambial aos preços ao consumidor, portanto são intervenções condizentes com o regime de metas, induzidas pelo fear of inflation. Para o Brasil, o autor estima que, dado um choque em $t=1$ de $1 \%$ na taxa de câmbio, ocorre uma variação de $1,3 \%$ no nível geral de preços em $t=12$, antes da adoção do regime de metas. Após a adoção, o impacto acumulado em 12 meses sobre o nível geral de preços é de apenas $0,11 \%$. Ou seja, o coeficiente de repasse, acumulado em 12 meses, decai muito no pe- 
ríodo sobre regime de metas; contudo é preciso cuidado ao afirmar que foi a adoção do regime o fator determinante para essa redução, pois, exceto pelo primeiro semestre de 1999, o período anterior ao regime de metas coincide com o período da âncora cambial, de modo que a redução brusca no repasse pode ser em parte explicada pela adoção do câmbio flutuante. Por meio da decomposição da variância dos erros de predição ortogonalizados (dentro da amostra, isto é, erros de ajustamento), o autor identifica que, após a adoção do regime de metas, há significativo aumento da parcela explicada pelas inovações sobre a inflação no erro de predição da taxa de juros em 12 meses (5,95\% antes do regime para 14,99\% após o regime, sendo essa proporção pós-regime a segunda maior entre os pesquisados, atrás apenas da África do Sul), o que indica que, como percebido por Minella et al. (2003), durante os anos iniciais do regime de metas, o BCB se manteve atento e reagiu com rigor a choques inflacionários. E ainda identifica redução do uso de reservas internacionais para intervir no mercado de câmbio no período sobre regime de metas, que coincide com o período de câmbio flutuante.

A questão da viabilidade do regime de metas para a inflação para economias em desenvolvimento, com baixa maturidade institucional e credibilidade por parte dos policymakers, sobretudo em ambiente de alta volatilidade cambial, ${ }^{22}$ foi tema de debate na macroeconomia internacional com autores como Guillermo Calvo, mais céticos quanto à capacidade de se implementar o regime de maneira funcional sem antes um amadurecimento institucional, e autores como Frederic Mishkin, advogando a favor do sistema, inclusive para economias em desenvolvimento, de que, se implementado com todos os requisitos como descritos em Mishkin (2000) e Mishkin e Savastano (2001), ${ }^{23}$ seria uma boa forma de acelerar o desenvolvimento das instituições de política econômica ${ }^{24}$ (CALVO e REINHART, 2002; CALVO e MISHKIN, 2003; MISHKIN, 2004). Calvo e Mishkin (2003) reconhecem peculiaridades de economias em desen-

${ }^{22}$ Como foi o ambiente em que se introduziu o regime de metas no Brasil (que foi oficialmente lançado pelo BCB em junho de 1999).

${ }^{23}$ Mishkin e Savastano (2001) destacam que, em sua visão, o país da América Latina que àquela altura tinha primeiro implementado e mais se aproximado do regime de metas, tal como eles descreviam, era o Brasil. Os autores destacam que um regime de metas de inflação se constitui não só pelo estabelecimento explícito de uma meta pontual para inflação acumulada em um dado período com bandas de tolerância e eventuais cláusulas de escape, mas também pela construção de uma autoridade monetária crível que eleja a estabilidade do crescimento do nível geral de preços como seu objetivo principal ao qual todos os demais estão subordinados, o que passa pela divulgação periódica de documentos explicando as razões de medidas tomadas e prospectos futuros para o cenário macroeconômico, de forma que haja completa transparência da política monetária e que, junto com outros marcos legais que punam o policymaker pelo descumprimento da meta, aumentem a accountability da autoridade monetária.

${ }^{24}$ Entendendo como desenvolvimento adotar políticas econômicas mais guiadas por regras com menor espaço para discrição. 
volvimento que favorecem maior instabilidade macroeconômica e especialmente cambial, como instituições fiscais mais propensas a gastos populistas e ciclos políticos, baixa credibilidade da autoridade monetária, mercados financeiros menos desenvolvidos, incluindo frágil regulação por parte do governo, tendência à dolarização de passivos (currency mismatch nos balanços do setor privado, isto é, grande volume de passivos em moeda estrangeira não compensados por ativos em moeda estrangeira, o que leva a flutuações no patrimônio líquido em reais decorrentes de flutuações cambiais) e ainda maiores riscos de substituição monetária e sudden-stops dos fluxos internacionais de capitais. ${ }^{25}$

Em tal ambiente institucional espera-se maior instabilidade macroeconômica em economias em desenvolvimento, e, dado o histórico de alta e instável inflação nesses países, sobretudo na América Latina, é justificável um maior repasse cambial nas economias em desenvolvimento em relação às desenvolvidas (GOLDFAJN e WERLANG, 2000; NOGUEIRA JÚNIOR, 2007; NORDSTROM et al., 2009). O que vai de encontro à tese de Taylor (2000), segundo a qual, em ambiente de menor credibilidade, com inflação mais alta e preços mais instáveis (maior volatilidade nominal), os formadores de preço levam menos em consideração em suas expectativas de inflação qualquer meta ou projeção de inflação anunciada pela autoridade monetária e se guiam mais por fatores outros, que podem variar muito entre os agentes econômicos, aumentando o disagreement nas expectativas de inflação, gerando assim maior incerteza. Nesse cenário mais incerto, os formadores de preço querem se proteger de perdas ao fixarem seus preços (não podem fixar alto demais e perderem marketshare, nem baixo demais e perderem oportunidades de lucro). Ocorre que, em cenário de incerteza com inflação elevada, aumentam as chances de que os formadores de preço concorrentes aumentem seus preços também, e provavelmente acima da meta ou projeção oficial, o que aumenta a propensão a reajustes de choques de custos, pois espera-se que seu concorrente faça o mesmo.

Um cenário de instabilidade monetária pode favorecer o maior repasse cambial por outro canal. Devereux et al. (2004) desenvolvem um modelo de equilíbrio geral em que o repasse cambial é endógeno, dependendo da proporção das firmas que exportam para um mercado local que adotam PCP (o que tende a elevar o repasse cambial), de modo que decisões de política monetária não podem ser tomadas assumindo

25 Kaltenbrunner e Painceira $(2012,2015)$ mostram como a melhora dos termos de troca da nossa economia impulsionada pelo "boom das commodities" permitiu ao banco central acumular grande volume de reservas cambiais, afastando-nos da restrição externa (insuficiência de dólares para saldar compromissos externos), mas criando novas instabilidades. 
o repasse cambial como dado. Em tal contexto os autores concluem que a escolha da moeda em que os preços de uma firma exportadora são fixados depende da volatilidade monetária relativa entre as economias em transação (no modelo, medida pela variância relativa do estoque de moeda de cada economia em relação às demais no cenário de comércio). Uma firma exportadora, quando se depara com grande volatilidade da taxa de câmbio entre sua moeda local e a moeda do país de destino, dados os custos de se proteger de frequentes e potencialmente intensas variações cambiais, tende a preferir comportamento de PCP (DEVEREUX et al., 2004), de outra forma, quando uma firma exportadora para a economia local tem parte relevante de seus insumos importados da economia local (e predomina nos setores de que importa PCP), tenderá a realizar LCP, pois tal comportamento automatiza um hedge cambial ${ }^{26}$ (AMITI et al., 2014). Portanto, a volatilidade no repasse cambial tem relação dúbia com o repasse cambial (BRUN-AGUERRE et al., 2012). E, ainda, por um aspecto microeconômico, alta volatilidade entre as moedas de um país de destino e a moeda do exportador leva um exportador que queira defender sua margem de lucro a preferir um comportamento de estabilização de preços na própria moeda; contudo, o ambiente competitivo e a importância relativa do mercado de destino podem implicar maior defesa da posição relativa do exportador diante de seus competidores nesse mercado, sendo, então, preferencial adotar um comportamento de estabilização dos preços no mercado de destino.

Contudo, essas relações não são simétricas entre os países, pois há mercados mais importantes do que outros, assim como moedas mais prevalentes no comércio internacional do que outras. Maior volatilidade da taxa euro-real faz com que, tudo o mais constante, um exportador da zona do euro prefira PCP, mas o contrário pode não estar disponível para um exportador brasileiro para a Europa, que tem menor poder de decisão, dado que o mercado europeu é muito grande e disputado e provavelmente será melhor para o exportador estabilizar seus preços em euro. Logo, o comportamento de PCP tende a predominar entre os exportadores de países desenvolvidos mais do que entre os exportadores de países em desenvolvimento para países usuários de moedas com alta liquidez internacional (superiores na hierarquia do sistema monetário), o que nos leva a esperar repasse cambial mais elevado para esses países em desenvolvimento do que para países centrais.

\footnotetext{
${ }^{26}$ Quando a moeda do mercado de destino se valorizar contra a sua moeda doméstica, haverá impacto de elevação sobre seus custos em moeda doméstica, mas, ao mesmo tempo, se seu preço na moeda do mercado de destino se mantém, há ganho de receita por unidade vendida em sua moeda local.
} 
Burnstein e Gopinath (2014) documentam evidências da literatura e apresentam outras de que o repasse cambial nos EUA é reduzido tanto no curto prazo quanto no longo, quando comparado com o de outros países desenvolvidos, o que, inclusive, estimulou pesquisas para investigar um suposto tratamento diferenciado do mercado estadunidense por parte de exportadores para essa economia (KNETTER, 1993). Knetter (1993) não identifica tal padrão de tratamento diferenciado por exportadores para a economia americana e encontra evidência de comportamento de pricing to market, favorecendo a abordagem microeconômica do repasse cambial ao identificar que o comportamento de precificação parece variar bem menos entre países do que entre setores, contudo deve-se destacar que o autor analisou EUA, Alemanha, Japão e Reino Unido, exatamente os emissores das moedas com maior liquidez internacional, isto é, dos passivos monetários do topo da hierarquia do sistema monetário, de modo que, do ponto de vista da hierarquia de moedas, não se espera um efeito relevante de decisões diferenciadas entre PCP e LCP sobre a variação do repasse entre esses países. Bussière et al. (2014) propõem que esse menor repasse cambial nos EUA se deve à distribuição geográfica de duas exportações, mais concentradas em países com alta elasticidade de repasse cambial para os preços de exportação. ${ }^{27}$ Também deve-se lembrar que o dólar americano é importante moeda-veículo para transações internacionais, sendo dominante na precificação de commodities (CALVO e MISHKIN, 2003; GOLDBERG e TILLE, 2016), de modo que, para vários setores nos EUA, existe um comportamento de fixação de preços no dólar americano por parte de seus competidores internacionais.

\section{A MICROECONOMIA DO REPASSE CAMBIAL}

Variações elevadas na taxa nominal de câmbio da moeda americana diante das moedas de seus principais parceiros comerciais nas décadas de 1970 e 1980, não acompanhadas por movimentos de magnitude similar, em um prazo razoavelmente curto, nos preços de importação da economia americana levaram à observação de que estavam ocorrendo choques persistentes sobre a taxa real de câmbio dos EUA. Desse modo, estava em cheque tanto a lei do preço único (associada à literatura de Purchasing Power Parity - PPP, que estabelece que o preço de um bem homogêneo entre países deve, numa mesma moeda, após descontados custos normais de distri-

27 Ou seja, economias em que em geral os exportadores absorvem em seus preços parte dos choques cambiais, reduzindo o ajuste sobre os preços at the dock nos mercados de destino. 
buição, ser o mesmo em todos os mercados em que é transacionado) ${ }^{28}$ como a PPP relativa (que, admitindo as diferenças de bens produzidos e negociados em economias diferentes, apenas exige que a taxa real de câmbio seja fixa em relação a choques nominais e não necessariamente como no caso da lei do preço único, ${ }^{29}$ de modo que as variações nos preços de um bem negociado em economias geograficamente separadas devem ser as mesmas quando convertidas para uma mesma moeda).

Assim começaram a surgir explicações teóricas que justificassem ao nível microeconômico repasses cambais incompletos (mesmo permitindo um lag temporal considerável entre o choque cambial e o último período de contabilização da variação, ceteris paribus, acumulada dos preços). Em 1986 e1987, Rudiger Dornbusch e Paul Krugman publicaram dois artigos que se tornariam clássicos na literatura de economia internacional. Dornbusch (1987) desenvolve modelos da tradição de organização industrial para o comércio internacional de forma que estabelece teoricamente que, dados os custos do trabalho entre duas economias distintas, os ajustes de preços em um setor em um mercado de destino dependem da substituibilidade entre os bens produzidos por cada firma nesse setor, do número de firmas domésticas em relação ao número de firmas estrangeiras e da estrutura de mercado na economia de destino. Krugman (1986) preocupa-se com a possibilidade de distinção de estratégias de precificação entre mercados segmentados com que uma firma exportadora se depara, o que é conhecido na literatura como pricing to market.

Campa e Goldberg (2005) destacam que o repasse de choques cambiais aos preços domésticos é tema de grande interesse na literatura econômica há um longo tempo, e que o foco do debate mudou, no início da década de 1980, da lei do preço único e da convergência de preços entre os países (em uma mesma moeda, dada a maior integração dos mercados internacionais) para o papel da organização industrial e da segmentação de mercados na discriminação de preços entre mercados geograficamente separados. Esses autores estudam o repasse cambial para preços de importação em 23 países da OCDE entre 1975 e 2003. Destacam evidência de repasse cambial incompleto no curto prazo, mas suas estimações para as elasticidades de longo prazo são condizentes com comportamento tipo PCP (repasse cambial completo para os preços de importação, ou seja, há rigidez de preços, mas em longo prazo exportadores parecem exercer relevante poder de mercado (BRUN-AGUERRE et al., 2017), e ainda que a volatilidade cambial está associada a um repasse cambial mais alto entre países, to-

\footnotetext{
28 Portanto exige mercados internacionais plenamente integrados.

29 Deve-se levarem conta que testes empíricos da lei do preço único precisam se restringir a bens que possam ser considerados homogêneos entre as distintas economias em análise.
} 
davia variáveis macroeconômicas desempenharam papel reduzido na variação temporal do repasse cambial, sendo muito mais importantes as mudanças na composição da pauta de importação das economias estudadas ao longo do tempo.

Campa et al. (2008) estudam não linearidades no repasse cambial entre 1989 e 2004 para países da União Europeia, tanto participantes da união monetária como membros originais da União Europeia que não aderiram ao euro, a partir de dados mensais desagregados para 12 categorias de produtos. Os autores partem da existência de uma relação log-linear de longo prazo (sem intercepto) entre o índice preços de produtos importados de uma dada categoria em um dado país, a taxa nominal de câmbio desse país em unidades de moeda doméstica por unidade de moeda estrangeira e o índice preços dos produtos dessa categoria no país exportador em moeda estrangeira, sem a imposição da lei do preço único. Por meio de modelos de correção de erros em painel, ${ }^{30}$ os autores buscam identificar a presença de não linearidades, tais como as descritas no parágrafo anterior para cada categoria de produto, ou seja, assumindo que existam características relativas à estrutura de mercado e/ou características dos próprios bens em cada categoria que interferem no repasse cambial. Concluem que a não proporcionalidade do choque é mais comum em preços de bens com maior capacidade de diferenciação e segmentação de mercado, não rejeitando a linearidade no repasse para commodities não agrícolas. No caso específico de bens industrializados houve maior evidência de assimetria, com ajustes a desvios da relação de longo prazo que levam a apreciações da moeda doméstica sendo mais rápidos que ajustes a desvios que levam a depreciações. E, por fim, identificaram intervalos nos desvios da relação de longo prazo, na ampla maioria dos casos, centrados em zero, para os quais não há ajuste nos preços, e estes foram maiores para commodities do que para bens industrializados. Os autores afirmam que (p. 6)

The observed evidence points to the existence of patterns of adjustment that are more homogeneous in an industry across countries than for different industries in a given country. We find strong evidence of the presence of non-linearities in the adjustment towards long-run equilibrium in certain industries.

Knetter (1993) também documenta maior variação setorial do que entre países em um estudo para EUA, Alemanha, Reino Unido e Japão.

\footnotetext{
${ }^{30}$ Para cada indústria se realiza um painel, ou seja, para cada indústria os dados variam no tempo e entre países.
} 
Auer e Schoenle (2016) estudam microdados das importações americanas e estabelecem algumas correlações entre o market share e as reações das firmas diante de variações na própria estrutura de custos e nos preços de concorrentes. Estabelecem que, em geral, as firmas que mais repassam choques de custo são as que menos reagem a mudanças de preços de concorrentes (menor rigidez real, isto é, menor sustentação do preço relativo da firma em um determinado setor). A relação repasse de variações nos custos (incluindo variações cambiais) e market share tem formato de U, isto é, firmas com grande participação no mercado e pequenas firmas tendem a ter maior repasse cambial do que firmas com participação no mercado intermediária. Quando se trata do repasse de variações nos preços das concorrentes (price complementarities) a correlação com o market share tem o formato inverso. Firmas grandes e bem estabelecidas tendem a ter alguma vantagem monopolística em relação às concorrentes, de modo que têm maior poder de repasse de choques sobre os próprios custos. Firmas pequenas em mercados mais competitivos são em geral tomadoras de preço, de modo que variações no custo marginal tendem a ser passadas aos preços, que teoricamente estão próximos destes, não havendo muito espaço para acomodações de variações de custo sobre as margens de lucro. Firmas intermediárias tendem a estar em disputa mais intensa por fatias do mercado e a ter alguma margem de acomodação em seus markups, o que favorece complementaridades de preços entre elas, induzindo maior sensibilidade a variações nos preços de concorrentes (maior rigidez real, isto é, rigidez da relação de preço da firma/nível de preço dos concorrentes). ${ }^{31}$

Contudo, essa explicação é só meia verdade, pois as estruturas de mercado são muito mais diversas. Por exemplo, uma firma pequena, que pode ser uma de algumas que disputam uma fatia minoritária de um mercado dominado por alguma empresa que tem alguma vantagem monopolística em relação às demais (marca de sucesso bem estabelecida no mercado e/ou a posse de alguma qualidade diferenciada que, por algum motivo, as demais não conseguem reproduzir), está mais capaz de defender sua margem de lucro enquanto as demais tendem a manter o preços relativos de seus produtos em relação à firma dominante constante, reagindo menos a variações nos custos que não afetam a firma dominante e reagindo em proporção de um para um quando a firma dominante reajusta preços. Ou seja, a estrutura de mercado parece ter importância central na determinação do repasse cambial, sendo a relação das firmas exportadoras com sua defesa de participação no mercado ou de margem de lucro, o que depende em boa parte do grau de competitividade do mercado, central para determinar o com-

${ }^{31}$ Concorrentes aqui podem ser todos os produtores de bens com relevante elasticidade de substituição pelo bem produzido pela firma. 
portamento do repasse cambial. Amiti et al. (2014) defendem teoricamente e encontram evidência empírica de que firmas com grande market share no mercado de destino e que ao mesmo tempo são grandes importadoras (e os autores evidenciam que grandes firmas exportadoras são em geral grandes importadoras) tendem a ter repasse cambial reduzido.

Herger (2015) parte de aspectos microeconômicos, ligados à decisão de uma firma de operar em determinado mercado diante de alterações significativas em sua estrutura de custos e lucros, para investigar não linearidade no repasse. O autor analisa a Suíça entre 1980 e 2013. A escolha da Suíça se faz pelo fato de ao longo do período estudado o país ter convivido com uma inflação baixa e estável, de maneira a evitar a possibilidade de haver regimes distintos de repasse cambial guiados por mudanças no ambiente inflacionário. Por meio de regressões com transição entre regimes (switching regressions), o autor identifica que há significativa elevação do repasse quando há grande desalinhamento cambial (moeda local é avaliada pelas firmas como supervalorizada ou subvalorizada). A intuição é que nesses casos ocorrem entradas e/ou saídas de firmas, o que altera dramaticamente o repasse cambial. $\mathrm{O}$ autor encontra evidência de assimetria com elevados repasses cambiais em momentos de rápida apreciação do franco suíço.

Do exposto até aqui pode-se inferir que há evidências de que o repasse cambial difira entre diferentes produtos a depender da estrutura de mercado, sobretudo com relação à competição (tanto questões como segmentação de mercado e capacidade de diferenciação de bens entre produtores são inter-relacionadas e impactam sobre o grau de competição entre os produtores concorrentes no mercado), o que indica que o repasse cambial agregado para uma dada economia depende da composição da pauta de importação do país e da possível existência de peculiaridades institucionais que criem distorções locais nos mercados de determinados produtos, afetando a competitividade de maneira idiossincrática em determinados mercados.

\section{DA ASSIMETRIA NO REPASSE CAMBIAL}

A assimetria no repasse cambial se refere à distintas reações dos preços agregados, a depender da direção do choque cambial. A assimetria para os preços de importação na economia doméstica pode ser explicada pelo poder de mercado de firmas exportadoras para a economia doméstica que são capazes de manter suas margens em moeda estrangeira quando há uma desvalorização cambial e obter ganhos quando há apreciação. Outra possibilidade é a existência de limitações nas redes de distribuição dos exportadores para a economia doméstica ou limitações à exportação nos países dos quais 
a economia doméstica importa, o que faz com que, em períodos de apreciação da moeda doméstica, o aumento da demanda por produtos importados, motivado pelo aumento do poder de compra internacional da moeda, leva, nesses casos, a pressões para o aumento de preço em moeda estrangeira dos bens importados, reduzindo o impacto da apreciação cambial (BRUN-AGUERRE, 2017).

Outra possibilidade originadora de assimetria no repasse cambial ocorre quando uma firma enfrenta razoável competição no mercado internacional e disputa participação em mercados estrangeiros. Em caso de apreciações da moeda de um país importador, a firma mantém seu preço na própria moeda e permite um repasse cambial completo ao preço em moeda do país importador, enquanto que, em caso de depreciações a fim manter seu market share, a firma exportadora absorve parte da perda de poder de compra da moeda do importador, reduzindo seu preço em sua moeda local, o que reduz o repasse ao preço pago pelo importador (PIMENTEL, 2017, p. 36-37). Esse pode ser um exemplo de pricing to market, quando a firma exportadora, diante de diferentes estruturas de mercados de venda (uma no mercado doméstico e outra nos mercados internacionais), discrimina preços entre esses mercados, o que a torna uma competidora mais agressiva em mercados internacionais (provocando a assimetria no repasse cambial acima descrita) e algo mais próximo de uma oligopolista no mercado doméstico (KRUGMAN, 1986).

Há ainda outra possível explicação teórica para assimetria no repasse que justifica repasses (deflacionários) de apreciações da moeda doméstica mais intensos do que os repasses (inflacionários) de depreciações, que pode ser vista por meio de um modelo neoclássico de comércio internacional que permite a possibilidade de mudanças de tecnologia de produção. Pense numa firma exportadora que tem insumos tanto domésticos quanto importados e preço fixado na moeda do país importador. Na ocorrência de uma apreciação da moeda do país importador, a firma pode mudar a combinação de insumos (mudança tecnológica), aumentando a proporção de insumos domésticos de forma a manter o custo marginal, em moeda local, inalterado (o que, com a apreciação da moeda do importador, significa que o custo marginal na moeda do importador se reduziu), e, dado o preço na moeda do país importador, há ganho de receita marginal em moeda local, o que estimula o aumento de produção. Em termos gráficos há um deslocamento da curva de oferta para a direita (pois houve um deslocamento da curva de custo marginal, na moeda do país importador, no mesmo sentido), e sendo essa firma representativa do conjunto das firmas do mercado em questão, há um deslocamento da curva de oferta do mercado para a direita, o que, dada a curva de demanda, reduz o preço na moeda do país importador. No caso de uma depreciação da moeda do país importador há uma mudança no sentido de aumentar a proporção de insumos importados de forma que há uma redução do custo marginal, 
em moeda local, e, dado o preço na moeda do país importador, uma redução da receita marginal, em moeda local, de modo que um efeito contribui para cancelar o outro, o que aponta para um deslocamento dúbio da curva de oferta do mercado, portanto, em geral, de menor intensidade que no caso de uma apreciação na moeda do importador.

Pollard e Coughlin (2004) encontram que em metade de 30 setores industriais, analisados nos EUA entre 1978 e 2000, há repasse cambial assimétrico no curto prazo, mas não há predominância de um tipo único de assimetria (maior para depreciação ou para apreciação da moeda doméstica). Bussière (2013), em um estudo dos países do G7, de 1980 a 2006, encontra tendência a maior repasse de depreciações do que de apreciações das moedas locais no curto prazo. Delatte e Lopez-Villavicencio (2012) estudam dados trimestrais de 1980 a 2009 para Japão, Alemanha, EUA e Reino Unido e encontram evidência de maior repasse a partir de depreciações de longo prazo.

No caso brasileiro, a literatura sobre assimetria no repasse cambial é ainda bastante escassa. Destacamos aqui Pimentel et al. (2016), Pimentel (2017) e Assis (2017).

Pimentel et al. (2016) estudam a assimetria no repasse cambial brasileiro por meio de Structural Vector Autoregressions (SVAR) para o período de janeiro de 1999 a maio de 2012. Estimam que o impacto inflacionário de uma desvalorização cambial é significativamente maior do que o impacto deflacionário de uma apreciação cambial. ${ }^{32}$ Os autores utilizam o IPCA como medida do nível geral de preços, o índice de produção física mensal da indústria, calculado pelo IBGE, como proxy para o nível de atividade estimulado pela demanda agregada, a média mensal da taxa de câmbio, e como proxies utilizadas em diferentes especificações para o comportamento dos custos (choques de oferta agregada), o índice de preços de commodities calculado pelo IPEA e a cotação do preço internacional do petróleo em dólares divulgada pelo FMI. Com diferentes especificações, sem incluir assimetria no repasse cambial, os autores estimaram, para o período de câmbio flutuante até maio de 2012, que, dada uma variação de $1 \%$ na taxa de câmbio em t, a inflação acumulada nos 12 meses seguintes aumenta algo entre 0,059p.p. e 0,072p.p. (são, respectivamente, o menor e o maior valores estimados nas diferentes especificações). Incluindo assimetria, uma apreciação de $1 \%$ na taxa de câmbio em $t$ leva a uma inflação adicional acumulada nos 12 meses seguintes de, curiosamente, 0024p.p. No caso de uma depreciação de $1 \%$, as estimações para a variação na taxa de inflação acumulada nos 12 meses seguintes ficaram entre 0,05p.p. e 0,069p.p.

Assis (2017) considera o nível de atividade (aproximado pelo índice de atividade econômica do BCB, o IBC-Br), a taxa nominal de câmbio (R\$/US\$), o nível de preços

\footnotetext{
32 Tal resultado é confirmado em um tratamento mais desagregado dos preços domésticos ao consumidor final em Pimentel (2017).
} 
(medido pelo IPCA) e a taxa Selic/over efetiva como variáveis endógenas da política monetária e as insere em um modelo VAR, com variáveis exógenas (nível de atividade do setor externo, preço internacional de commodities e CPI dos EUA). A análise se faz de agosto de 2003 a agosto de 2016. O autor encontra em diferentes especificações (deflaciona-se ex-ante e ex-post a taxa básica de juros e se considera assimetria no repasse cambial) relação de cointegração entre a taxa de juros, o índice de preços e o nível de atividade, o que leva à estimação de modelos vetoriais de correção de erros (VECM). Diferentemente de Pimentel et al. (2016), Assis (2017) encontra evidência de maior impacto deflacionário quando há apreciação do real diante do dólar do que inflacionário quando há depreciação. O repasse cambial em 12 meses é de 21,29\% em caso de apreciação e 8,54\% em caso de depreciação, e o de longo prazo é 23,32\% em caso de apreciação do real e 10,34\% em caso de depreciação. Destaca-se ainda que a inclusão de controles exógenos reduziu a resposta dos preços a choques na própria série de preços e aumentou a resposta a choques cambiais, o que indica que no período estudado a ausência de controles para choques externos leva a uma subestimação do repasse cambial e a uma superestimação da inércia inflacionária. ${ }^{33}$

\section{CONCLUSÃO}

Este trabalho revisou a literatura sobre repasse cambial, dando ênfase às mensurações realizadas para o Brasil. Depreendemos da literatura dois grandes fatores de determinação do repasse: o ambiente inflacionário e a composição das cestas de importação. Há ainda um terceiro, que é mais importante para explicar a distinção entre grupos de países e o repasse cambial reduzido dos EUA, que não aparece explicitamente em nenhum dos artigos revisados, que é a importância da hierarquia de moedas. Essa importância se revela em duas situações. Uma é considerar que economias com moedas com baixa liquidez internacional tendem a apresentar maior vulnerabilidade externa, portanto são mais sujeitas a choques cambiais e a maior pressão no grau de repasse do câmbio aos preços. Outro aspecto importante opera por meio das tendências de precificação em moedas das economias centrais por parte de exportadores de países em desenvolvimento e de PCP pelos exportadores nas economias centrais. Essa tendência

\footnotetext{
${ }^{33}$ Vale acrescentar que o autor também identificou que, para o Brasil, o IPA tende a ter maior sensibilidade à taxa de câmbio, e, por consequência, ao IGP (o IPA representa $60 \%$ do IGP), do que ao IPCA. Dado que o IGP é usado como índice de referência para reajuste de diversos preços contratados (o IGP-M é a referência para alugueis, por exemplo), isso é evidência favorável ao achado de Minella et al. (2003), de que os preços administrados são mais sensíveis a flutuações cambiais que os preços livres.
} 
de precificação na moeda com maior grau de liquidez internacional tende a gerar menor repasse nas economias detentoras de moedas com liquidez internacional elevada (como países da zona do euro, EUA, Japão e Reino Unido) em relação a países em desenvolvimento.

Acreditamos que há pouca precisão na pergunta se o "repasse cambial é um fenômeno macro ou microeconômico?". A divisão macro ou micro nesse caso tem muito mais a ver com a abordagem e com o interesse analítico do que com o estudo de fenômenos distintos. A questão que muitas vezes se coloca é: qual dos grandes fatores, de fato, tem maior preponderância sobre as flutuações do repasse cambial? Se é o ambiente inflacionário, a estabilização e maior equalização das taxas de inflação ao redor do mundo devem promover uma grande convergência do repasse cambial. E, em caso de um eventual ressurgimento de uma inflação mais alta em todo o globo, deveríamos observar repasses cambiais maiores no curto prazo e muito mais evidências de repasse cambial de longo prazo completo (ou algo mais próximo disso). Se são as mudanças na composição da pauta de importação, então o repasse cambial deve variar mais fortemente entre setores produtivos do que entre países. Nesse caso, os fatores quantitativamente mais importantes para o repasse cambial estão relacionados às estruturas de mercado. Ou seja, o que de fato interessa saber é se as variáveis que caracterizam o ambiente de negócios em uma economia têm poder explicativo superior a fatores que variam no nível setorial ou ainda das firmas, ou é justamente o oposto.

Se focarmos em aspectos macroeconômicos, vemos que o repasse depende do ambiente inflacionário, das condições de demanda agregada, da abertura comercial, das expectativas quanto à persistência de choques sobre a série da taxa de câmbio, da volatilidade da taxa de câmbio e das percepções dos agentes quanto à política cambial.

Tomando o ambiente inflacionário, por exemplo, temos que a alta inflação eleva a incerteza e aumenta a persistência da série de inflação (TAYLOR, 2000; MANKIW et al., 2003), o que eleva o impulso de empresários de repassar choques de custos. Mas só o impulso não basta, é preciso considerar a capacidade de manter a taxa de markup e a sensibilidade, percebida pela firma, de seu market share a elevações de preço. Tais questões de impulso e a capacidade das firmas de variar seus preços em virtude de choques cambiais dependem essencialmente de expectativas e do poder de mercado. As expectativas de uma firma estão ligadas a todos os aspectos macroeconômicos que afetam o repasse, anteriormente citados, mas também a realidade do entorno do empresário. O poder de mercado depende essencialmente da estrutura de mercado, que, por sua vez, é determinada, fundamentalmente, pelas características do bem transacionado e por aspectos institucionais. Essa visão é corroborada pela evidência de variação de repasse entre setores produtivos e similaridade de um mesmo setor entre países (CAMPA et al., 2008) e pelo decaimento do repasse ao longo da cadeia produ- 
tiva (choques cambiais afetam taxas relativas de markup e/ou alteram estruturas de custos). O repasse agregado para um determinado conjunto de preços depende das características dos bens que compõem o conjunto em análise, pois estas, juntamente com aspectos institucionais, determinam as estruturas de mercado. A estrutura de mercado em que a firma atua é determinante para a formação de sua estratégia e poder de mercado, elementos centrais para a determinação da propensão e capacidade de repasse aos preços de choques que afetam sua estrutura de custos.

Dada a documentada heterogeneidade setorial no repasse cambial (CAMPA e GOLDBERG, 2005; CAMPA et al., 2008; GOLDBERG e TILLE, 2015; AUER e SCHOENLE, 2016), não é possível que desprezemos a composição das pautas de importação de uma economia na determinação do repasse cambial, e é preciso reconhecer o papel de idiossincrasias locais, que, por exemplo, podem afetar as estruturas de mercado. Krugman (1986) e Knetter (1993) mostram que mercados segmentados podem determinar repasses significativamente diferentes, mesmo em economias que possuam o mesmo regime cambial, pautas de importação de composição parecidas e processos inflacionários similares. Brun-Aguerre et al. (2012), por exemplo, encontram que aspectos econômicos dos mercados de destino, como volatilidade cambial, inflação, hiato do produto, riqueza, dependência de produtos importados, protecionismo e não linearidades (ligadas à direção e tamanho da variação cambial), explicam aproximadamente $1 / 3$ da variação no repasse cambial entre países e no tempo, estando os $2 / 3$ em maior parte explicados por idiossincrasias locais das economias de destino.

Em relação a estudos recentes sobre o repasse cambial para a economia brasileira, destacamos Pimentel (2017) e Assis (2017). Em ambos os estudos se identificou que a taxa de câmbio é variável importante na determinação da inflação dos preços domésticos, não se podendo desprezar os efeitos do repasse cambial.

Por fim, do ponto de vista empírico ainda há muito que se explorar a respeito das não linearidades da relação da taxa de câmbio com os preços domésticos no Brasil, já havendo evidência de assimetria no repasse, mas ainda sem direcionamento claro. $\mathrm{E}$ também é necessário construir e explorar bases de dados mais desagregadas referentes a nosso comércio exterior na tentativa de investigar heterogeneidades setoriais no repasse cambial e, na medida do possível, avaliar como a mudança na composição de nossa pauta de importação (como, por exemplo, a participação de determinados manufaturados, classificados possivelmente por nível tecnológico) pode ter afetado o repasse ao longo do tempo. 


\section{REFERÊNCIAS}

ALBUQUERQUE, C. R.; PORTUGAL, M. S. Pass-through from exchange rate to prices in Brazil: an analysis using time-varying parameters for the 19802002 period. Revista de Economía, v. 12, n. 1, p. 17-74, 2005.

ALMENDRA, P. N. V.; PORTUGAL, M. S.; DE MACÊDO, G. R. Pass-through da taxa de câmbio para a inflação no Brasil: Um estudo econométrico utilizando o filtro de Kalman. In: ENCONTRO NACIONAL DE ECONOMIA, 43., Florianópolis, SC, 8-11 nov. 2015.

AMITI, M.; ITSKHOKI, O.; KONINGS, J. Importers, exporters, and exchange rate disconnect. American Economic Review, v. 104, p. 1942-1978, 2014.

ASSIS, T. M. A taxa de câmbio no regime de metas para a inflação no Brasil: mecanismos de transmissão, intervenção e repasse cambial. Dissertação (Mestrado em Economia) - Departamento de Economia, Universidade Federal Fluminense, Niterói, RJ, 2017.

ATKESON, A.; BURSTEIN, A. Pricing-to-market, trade costs, and international relative prices. American Economic Review, v. 98, p. 1998-2031, 2008.

AUER, R. A.; SCHOENLE, R. S. Market structure and exchange rate pass-through. Journal of International Economics, v. 98, p. 60-77, 2016.

BALL, C. P.; REYES, J. A. Inflation targeting or fear of floating in disguise: a broader perspective. Journal of Macroeconomics, v. 30, n. 1, p. 308-326, 2004.

BARBOSA-FILHO, N. H. Inflation targeting in brazil: 1999-2006. International Review of Applied Economics, v. 22, n. 2, p. 187-200, 2008.

BELAISCH, A. Exchange rate pass-through in Brazil. IMF Working Paper Series, v. 03, n. 141, 2003.

BRUN-AGUERRE, R.; FUERTES, A. M.; PHYLAKTIS, K. Country and time variation in import pass-through: macro versus micro factors. Journal of International Money and Finance, v. 31, p. 818-844, 2012.

BRUN-AGUERRE, R; FUERTES, A. M.; GREENWOOD-NIMMO, M. Heads I win; tails you lose: asymmetry in exchange rate pass-through into import prices. Journal of the Royal Statistical Society, Series A, v. 180, n. 2, p. 587-612, 2017.

BUSSIẼRE, M. Exchange rate pass-through to trade prices: the role of nonlinearities and asymmetries. Oxford Bulletin of Economics and Statistics, v. 75, p. 731-758, 2013.

BURSTEIN, A.; GOPINATH, G. "International prices and exchange rates". In: GOPINATH, G.; HELPMAN, E.; ROGOFF, K. (Eds.). Handbook on International Economics. v. 4. 4. ed. Amsterdam: Elsevier, p. 391-451, 2014.

BURSTEIN, A.; EICHENBAUM, M.; REBELO, S. Large devaluations and the real exchange rate. Journal of Political Economy, v. 113, p. 742-784, 2005.

BUSSIÈRE, M.; DELLE CHIAIE, S.; PELTONEN, T. Exchange rate pass-through in the global economy: the role of emerging market economies. IMF Economic Review, v. 62, p. 146-178, 2014.

CALVO, G.; REINHART, C. Fear of floating. The Quarterly Journal of Economics, v. 117, n. 2, p. 379-408, 2002. 
CALVO, G.; MISHKIN, F.S. The Mirage of Exchange rate regimes for emerging market countries. The Journal of Economic Perspectives, v. 17, n. 4, p. 99-118, 2003.

CAMPA, J. M.; GOLDBERG, L. S. Exchange rate pass-through into import prices. Review of Economics and Statistics, v. 87, p. 679-690, 2005.

CAMPA, J. M.; GONZALEZ MINGUEZ, J. M.; BARRIEL, M. S. Non-linear adjustment of import prices in the European Union. Working Paper, Bank of England, n. 347, 2008.

CAPISTRÁN, C.; IBARRA, R.; Francia, R. El traspaso de los movimientos del tipo de cambio a los precios. El Trimestre Económico, LXXIX, n. 4, p. 813-838, 2012.

CHOUDHRI, E. U.; FARUQEE, H.; HAKURA, D. S. Explaining the exchange rate pass-through in different prices. Journal of International Economics, v. 65, n. 2, p.349-374, 2005.

CHOUDHRI, E. U.; HAKURA, D. S. Exchange rate pass-through to domestic prices: does the inflationary environment matter? Journal of International Money and Finance, v. 25, n. 4, p. 614-639, 2006.

CORDEN, W. M. Exchange rate regimes for emerging markets: lessons from Asia. Annals of the American Academy of Political and Social Science, p. 26-37, 2002.

DELATTE, A. L.; LÓPEZ-VILLAVICENCIO, A. Asymmetric exchange rate pass-through: Evidence from major countries. Journal of Macroeconomics, v. 34, n. 3, p. 833-844, 2012.

DORNBUSCH, R. Exchange rates and prices. American Economic Review, v. 77, n. 1, p. 93-106, 2987.

DEVEREUX, M. B.; ENGEL, C.; STORGAARD, P. E. Endogenous exchange rate pass-through when nominal prices are set in advance. Journal of International Economics, v. 63, p. 263$291,2004$.

DONAYRE, L.; PANOVSKA, I. State-dependent exchange rate pass-through behavior. Journal of International Money and Finance, v. 64, p. 170-195, 2016.

FRITZ, B.; PAULA, L. F. de; PRATES, D. M. Global currency hierarchy and national policy space: a framework for peripheral economies. European Journal of Economics and Economic Policies: Intervention, v. 15, n. 2, p. 208-218, 2018.

GHOSH, A. R.; OSTRY, J. D.; CHAMON, M. Two targets, two instruments: Monetary and exchange rate policies in emerging market economies. Journal of International Money and Finance, v. 60, p. 172-196, 2016.

GOLDBERG, L. S.; TILLE, C. Micro, macro, and strategic forces in international trade invoicing: Synthesis and novel patterns. Journal of International Economics, v. 102, p. 173-187, 2016.

GOLDFAJN, I.; WERLANG, S. R. C. The pass-through from depreciation to inflation: a panel study. BCB Working Papers Series, v. 5, 2000.

HERGER, N. Market entries and exits and the nonlinear behavior of the Exchange rate passthrough into import prices. Open economies Review, v. 26, n. 2, p. 313-332, 2015.

JUNTILLA, J.; KORHOEN, M. The role of inflation regime in the exchange rate pass-through to import prices. International Review of Economics \& Finance, v. 24, p. 88-96, 2012.

KALTENBRUNNER, A. A post Keynesian framework of exchange rate determination: a Minskyan approach. Journal of Post Keynesian Economics, v. 38, n. 3, p. 426-448, 2015. 
KALTENBRUNNER, A.; PAINCEIRA, J. P. The impossible trinity on "steroids": Inflation targeting and exchange rate management in emerging markets. AUGUR Working Paper, 2012.

KALTENBRUNNER, A.; PAINCEIRA, J. P. Developing countries' changing nature of financial integration and new forms of external vulnerability: The Brazilian experience. Cambridge Journal of Economics, v. 39, n. 5, p. 128-1306, 2015.

KNETTER, M.M. International comparisons of pricing to market behavior. American Economic Review, v. 83, p. 473-486, 1993.

KRUGMAN, P. Pricing to market when the exchange rate changes. NBER Working Paper, $\mathrm{n}$. 1926, 1986.

LIN, P. C.; WU, C. S. Exchange rate pass-through in deflation: The casa of Taiwan. International Review of Economics \& Finance, v. 22, n. 1, p. 101-111, 2012.

MANKIW, N. G.; REIS, R.; WOLFERS, J. Disagreement about inflation expectations. NBER Macroeconomics Annual, v. 18, p. 209-248, 2003.

MCCARTHY, J. Pass-through of exchange rates and import prices to domestic inflation in some industrialized economies. Fed Nova York Staff Report 111, 2000.

MENDONÇA, H. F. de; TOSTES, F. S. The effect of monetary and fiscal credibility on exchange rate pass-through in an emerging economy. Open Economies Review, v. 26, n. 4, p. 787-816, 2015.

MENDONÇA, H. F. de; TIBERTO, B. P. Effect of credibility and exchange rate pass-through on inflation: an assessment for developing countries. International Review of Economics \& $\mathrm{Fi}$ nance, v. 50, p. 196-244, 2017.

MINELLA, A. et al. Inflation targeting in Brazil: Constructing credibility under exchange rate volatility. Journal of International Money and Finance, v. 22, n. 7, p.1015-1040, 2003.

MISHKIN, F. S. Inflation targeting in emerging-market countries. American Economic Review, v. 90, n. 2, p. 105-109, 2000.

MISHKIN, F. S. Can inflation targeting work in emerging market countries? Technical report. NBER Working Paper, n. 10646, 2004.

MISHKIN, F. S.; SAVASTANO, M. A. Monetary policy strategies for Latin America. Journal of Development Economics, v. 66, n. 2, p. 415-444, 2001.

NOGUEIRA JUNIOR, R. P. Inflation targeting and exchange rate pass-through. Economia Aplicada, v. 11, n. 2, p. 189-208, 2007.

NORDSTROM, A. et al. The role of the exchange rate in inflation: targeting emerging economies. IMF Occasional Papers, n. 267, Nov. 2009. Disponível em: <https://www.imf.org/en/ Publications/Occasional-Papers/Issues/2016/12/31/The-Role-of-the-Exchange-Rate-in-Inflation-Targeting-Emerging-Economies-Targeting-Emerging-22479>. Acesso em: 31 jan. 2019.

PAULA, L. F. de; FRITZ, B.; PRATES, D. M. Keynes at the periphery: Currency hierarchy and challenges for economic policy in emerging economies. Journal of Post Keynesian Economics, v. 40, n. 2, p. 183-202, 2017.

PIMENTEL, D. M. Dinâmica inflacionária no Brasil pós-Real: transmissão assimétrica de preços em uma abordagem desagregada. Tese (Doutorado em Economia) - Instituto de Economia, Universidade Federal do Rio de Janeiro, Rio de Janeiro, 2017. 
PIMENTEL, D. M.; LUPORINI, V.; MODENESI, A. M. Assimetrias no repasse cambial para a inflação: uma análise empírica para o brasil (1999 a 2013). Estudos Econômicos, v. 46, n. 2, p.343-372, 2016.

POLLARD, P. S.; COUGHLIN, C. C. Size matters: asymmetric exchange rate pass-through at the industry level. Working Paper, Federal Reserve Bank of St Louis, St Louis, n. 2003-29C, 2004.

PRATES, D. M. As assimetrias do sistema monetário e financeiro internacional. Revista de Economia Contemporânea, v. 9, n. 2, p. 263-288, 2005.

ROSSI, P. Padrões de integração financeira e a volatilidade das taxas de câmbio e juros em países periféricos. OIKOS, v. 9, n. 1, 2010.

TAYLOR, J. B. Low inflation, pass-through, and the pricing power of firms. European economic review, v. 44, n. 7, p. 1389-1408, 2000.

WRAY, L. R. Understanding modern money. v. 11. Cheltenham: Edward Elgar, 1998. 